\section{Programa de Profilaxis Pre-exposición contra el VIH (PreP) del Ministerio de Salud en Chile}

\section{Program of Pre-exposure Prophylaxis against HIV (PreP) of the Ministry of Health in Chile}

\section{Señor Editor,}

En la edición de Junio de 2020 de su prestigiosa revista, se publicó el artículo "Evaluación de la Infección por VIH en Chile: pronunciamiento del comité de VIH de

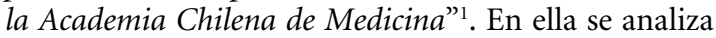
la infección por VIH, sus cambios epidemiológicos en los últimos años, y los avances en su tratamiento en Chile, con la incorporación del VIH dentro de las patologías del Plan de Garantías Explícitas en Salud. Entre las brechas por superar se mencionan mejoras en los programas de educación sexual y de prevención. En este punto, es importante destacar el programa PreP (profilaxis pre-exposición de $\mathrm{VIH}$ ) recientemente incorporado como política de salud pública del Ministerio de Salud de Chile (MINSAL).

El PreP o profilaxis preexposición consiste en el uso diario de antivirales orales inhibidores nucleosídicos de la transcriptasa reversa del VIH: tenofovir y emtricitabina, que está avalado por los estudios iPrEX, iPERGAY, PartnersPreP entre otros ${ }^{2,3,4}$. La entrega de PreP por parte del MINSAL se inició en el 2019 a grupos específicos con mayor riesgo de contagio (por vulnerabilidades específicas), como población transgénero, hombres que tienen sexo con hombres, trabajadores del comercio sexual, y además en parejas serodiscordantes. Entre los criterios de inclusión la "Orientación técnica 2019 para Profilaxis Preexposición (PreP) a la infección por $V I H^{\prime \prime}$, señala que los criterios de inclusión a PreP son ser beneficiario de FONASA o PRAIS con estatus VIH negativo, mayor de 18 años, sexualmente activo, que en los últimos 6 meses haya tenido relaciones sexuales anales sin condón con más de una pareja, o historia de ITS, o pareja sexual con uno o más factores de riesgo para VIH, o uso de drogas recreativas en el contexto de relaciones sexuales. El programa PreP además de entregar la profilaxis, se encarga de educar y reforzar el uso del preservativo, aplica inmunoprofilaxis contra otras ITS (hepatitis A, B y virus papiloma humano), y realiza controles periódicos de los usuarios PreP de VIH y otras ITS (sífilis, gonococo, hepatitis B y C), además de controles de función renal y hepática. Este programa se ha encargado de incluir a la población transgénero, que es particularmente susceptible a la infección por VIH por diversos factores bio-psico-sociales, y cuya prevalencia de la infección por VIH pueden llegar hasta
$30 \%$ en algunos países latinoamericanos vs $0,8 \%$ en la población general ${ }^{6}$.

Este tipo de profilaxis contra el VIH es importante tenerla en cuanta considerando el bajo porcentaje de uso de preservativo en nuestra población, como una alternativa más para la prevención de la expansión de la infección por VIH.

\section{Antonio Zapata Pizarro ${ }^{1,2}$, Cristina Muena Bugueño ${ }^{1,3}$, Susana Quiroz Nilo, José Valenzuela Cruz ${ }^{2}$ \\ ${ }^{1}$ Unidad de Incongruencia de Género. Hospital Regional de Antofagasta, Chile. \\ ${ }^{2}$ Departamento de Medicina Interna Facultad de Medicina. Universidad de Antofagasta, Chile. ${ }^{3}$ Programa PreP (profilaxis pre-exposición de VIH). Hospital Regional de Antofagasta, Chile.}

\section{Referencias}

1. Wolff M, Pinto M, Santolaya M, Aguilera X, Child R. Evaluación de la infección por VIH en Chile: Pronunciamiento del Comité de VIH de la Academia Chilena de Medicina 2020; 148: 818-21.

2. Grant R, Lama J, Anderson P, McMahan V, Liu A, Vargas $\mathrm{L}$, et al. Preexposure Chemoprophylaxis for HIV prevention in menwho have sex with men. N. Engl J Med 2010; 363: 2587-99.

3. Molina M, Capitant C, Spire B, Pialoux G, Cotte L, Charreau I. On-Demand preexposure prophylaxis in men at high risk for HIV-1 infection. N Engl J Med 2015; 373: 2237-46.

4. Baeten J, Donell D, Ndase P, Mugo N. Antiretroviral Prophylaxis for HIV prevention in heterosexual men and women. N Engl J Med 2012; 367: 399-410.

5. En diprece.minsal.cl/wp-content/uploads/2019/08/OT2019-Profilaxis-Pre-Exposici\%C3\%B3n-PrEP-a-la-infecci\%C3\%B3n-por-VIH.pdf [Revisado en junio de 2020].

6. Respuesta al VIH en América Latina. Comunidades en el centro. Actualizaciones sobre datos globales sobre SIDA 2019 www.unaids.org/sites/default/files/media_asset/2019-global-AIDS-update_latin-america_es.pdf [revisado en junio de 2020].

Correspondencia a:

Dr. Antonio Zapata Pizarro

Hospital Regional de Antofagasta

Antofagasta, Chile.

amzapatap@gmail.com 